\title{
PENGARUH KEPEMIMPINAN, MOTIVASI, DAN KOMPENSASI TERHADAP KEPUASAN KERJA KARYAWAN (STUDI KASUS PADA PERUSAHAAN IMPORTIR ALAT BERAT PT XYZ DI JAKARTA)
}

\author{
Nurhaiyati \\ Program Studi Magister Manajemen Universitas Tarumanagara \\ nurhaiyati@ hotmail.com \\ Nurahma Tresani \\ Program Studi Magister Manajemen Universitas Tarumanagara \\ Masuk : 06-06-2020, revisi : 24-06-2020 diterima untuk diterbitkan : 24-06-2020
}

\begin{abstract}
The purpose of this research is to investigate the effect of leadership, motivation and compensation on employee job satisfaction in a heavy equipment importer company PT XYZ in Jakarta. The population of this research was 115 people and the sample were selected using a probability sampling method totaling 110 respondents in Jakarta. Data processing techniques using the Structural Equation Model (SEM) method which is assisted by Smart PLS software.3.3.2. The results of this research indicate that leadership, motivation, and compensation have a significant positive effect on employee job satisfaction. Leaders who provide opportunities to their employees in achieving company goals, employees who have high motivation in working and provide fair and transparent incentives in accordance with the work performance achieved are known to increase employee job satisfaction.
\end{abstract}

Keywords: Leadership, Motivation, Compensation, Job Satisfaction

Abstrak: Tujuan dari penelitian ini adalah untuk mengetahui pengaruh dari kepemimpinan, motivasi dan kompensasi terhadap kepuasan kerja karyawan pada sebuah perusahaan importir alat berat PT XYZ di Jakarta. Populasi penelitian ini sebanyak 115 orang dan sampel dipilih menggunakan metode probability sampling berjumlah 110 orang responden di Jakarta. Teknik pengolahan data menggunakan metode Structural Equation Model (SEM) yang dibantu oleh perangkat lunak Smart PLS.3.3.2. Hasil penelitian ini menunjukkan bahwa kepemimpinan, motivasi, dan kompensasi berpengaruh secara positif signifikan terhadap kepuasan kerja karyawan. Pimpinan yang memberikan kesempatan kepada karyawannya dalam mencapai tujuan perusahaan, karyawan yang mempunya motivasi yang tinggi dalam bekerja dan pemberian insentif yang adil serta transparan sesuai dengan prestasi kerja yang dicapai diketahui dapat meningkatkan kepuasan kerja karyawan.

Kata Kunci: Kepemimpinan, Motivasi, Kompensasi, Kepuasan Kerja

\section{PENDAHULUAN}

Menurut Yakub (2017), kepuasan kerja bukanlah satu variabel yang berdiri sendiri, melainkan dipengaruhi oleh berbagai faktor baik yang bersumber dari dalam organisasi maupun yang bersumber pada diri pegawai itu sendiri. Faktor-faktor yang mempengaruhi kepuasan atau ketidakpuasan kerja yaitu: jenis pekerjaan, rekan kerja, tunjangan, perlakuan yang adil, keamanan kerja, peluang menyumbang gagasan, gaji, dan kesempatan berkembang (Lantara, 2017). Sedangkan Robbins \& Judge (2011) menyatakan faktor-faktor yang mengukur kepuasan kerja adalah sifat pekerjaan, pengawasan, bayaran saat ini, peluang promosi dan rekan kerja.

Kepuasan kerja dapat dicapai apabila karyawan produktif dalam bekerja dan harapan karyawan dapat dipenuhi oleh perusahaan. Jika pemimpin atau rekan kerja tidak saling mendukung atau saling tidak memperdulikan satu sama lain maka pekerjaan yang dilaksanakan 
tidak akan berjalan dengan baik dan akan menimbulkan masalah dan secara otomatis kepuasan kerja karyawan sudah pasti menurun. Pemimpin dan rekan kerja sebaiknya saling memahami dan memotivasi satu sama lain agar tercipta hubungan kerja yang baik. Hubungan kerja yang baik akan menciptakan kepuasan kerja bagi karyawan (Harahap dan Khai, 2019).

Kepuasan kerja tidak dapat dipisahkan oleh motivasi kerja yang seringkali merupakan harapan bagi karyawan. Gambaran yang akurat tentang hubungan ini adalah bahwa motivasi kerja dapat menimbulkan kepuasan kerja yang tinggi, kepuasan kerja akan tinggi apabila keinginan dan kebutuhan karyawan dalam bekerja terpenuhi maka motivasi kerja akan terwujud dengan baik. Menurut Hasibuan (2016), motivasi adalah pemberian daya penggerak yang menciptakan gairah kerja seseorang agar mereka mau bekerja sama, bekerja efektif, dan berintegrasi dengan segala daya upayanya untuk mencapai kepuasan yang diinginkan.

Salah satu cara yang dapat ditempuh oleh organisasi untuk meningkatkan prestasi kerja, motivasi dan kepuasan kerja karyawan adalah melalui kompensasi. Kompensasi adalah segala sesuatu yang diterima karyawan sebagai balas jasa atas kerja yang telah dilakukan. (Laminingrum, 2016).

\section{Tujuan Penelitian}

Adapun tujuan dari penelitian ini adalah untuk mengetahui pengaruh:

1. Kepemimpinan terhadap kepuasan kerja karyawan

2. Motivasi terhadap kepuasan kerja karyawan

3. Kompensasi terhadap kepuasan kerja karyawan

\section{TINJAUAN PUSTAKA}

\section{Kepuasan Kerja Karyawan}

Menurut Wibowo (2015), kepuasan kerja adalah merupakan tingkat perasaan senang seseorang sebagai penilaian positif terhadap pekerjaannya dan lingkungan tempat pekerjaannya. Sedangkan Usman (2011), menyatakan bahwa kepuasan kerja adalah terpenuhinya seluruh kebutuhan pekerja dalam melaksanakan tugasnya waktu tertentu. Kemudian Davis dalam Mangkunegara (2017) menyatakan bahwa kepuasan kerja adalah perasaan yang menyokong atau tidak menyokong dalam diri pegawai dalam bekerja.

\section{Kepemimpinan}

Menurut Baihaqi (2015), kepemimpinan adalah suatu proses mempengaruhi atau menggerakkan. Dengan kata lain kepemimpinan merupakan kemampuan untuk memengaruhi dan menggerakkan bawahan atau anggota organisasi untuk mencapai visi atau tujuan yang telah ditetapkan suatu kelompok. Kepimpinan adalah kemampuan dalam mengarahkan, mempengaruhi dan mengawasi para bawahannya agar mereka mau bertindak, berperilaku dan berkarya sedemikian rupa sehingga mampu memberikan pekerjaan yang baik demi mencapainya tujuan perusahaan (Harapan dan Khair, 2019). Berbeda dengan Siagian (2002) yang mengemukakan bahwa kepemimpinan adalah kemampuan seseorang untuk mempengaruhi orang lain (para bawahannya) sedemikian rupa sehingga orang lain itu mau melakukan kehendak pemimpin meskipun secara pribadi hal itu mungkin tidak disenanginya.

\section{Motivasi}

Motivasi adalah kesediaan melakukan usaha tingkat tinggi guna mencapai sasaran organisasi yang dikondisikan oleh kemampuan usaha tersebut memuaskan kebutuhan sejumlah individu (Sarittama dan Noerman, 2017). Manullang (2013) menyatakan bahwa motivasi adalah suatu kekuatan dari dalam atau luar diri manusia untuk mendorong semangat untuk mengejar sesuatu keinginan dan tujuan tertentu. Sedangkan Sutrisno (2013) menyatakan bahwa motivasi adalah suatu faktor yang mendorong seseorang untuk melakukan suatu aktivitas tertentu, oleh karena itu motivasi sering kali diartikan pula sebagai faktor pendorong perilaku seseorang. Setiap aktivitas yang dilakukan oleh seseorang pasti memiliki suatu faktor yang mendorong aktivitas tersebut. 


\section{Kompensasi}

Handoko (2012) menyatakan bahwa kompensasi adalah segala sesuatu yang diterima oleh para karyawan sebagai balas jasa untuk kerja mereka. Compensation is who employee receive inexchange of their work, whether hourly wages or periodic salaries, the personnel department usually design and administers employee compensation (Werther, William and Davis, 2002). Sedangkan Hasibuan (2016) menyatakan bahwa kompensasi adalah semua pendapatan yang berbentuk uang, barang langsung atau tidak langsung yang diterima karyawan sebagai imbalan atas jasa yang diberikan kepada perusahaan.

\section{Kerangka Pemikiran}

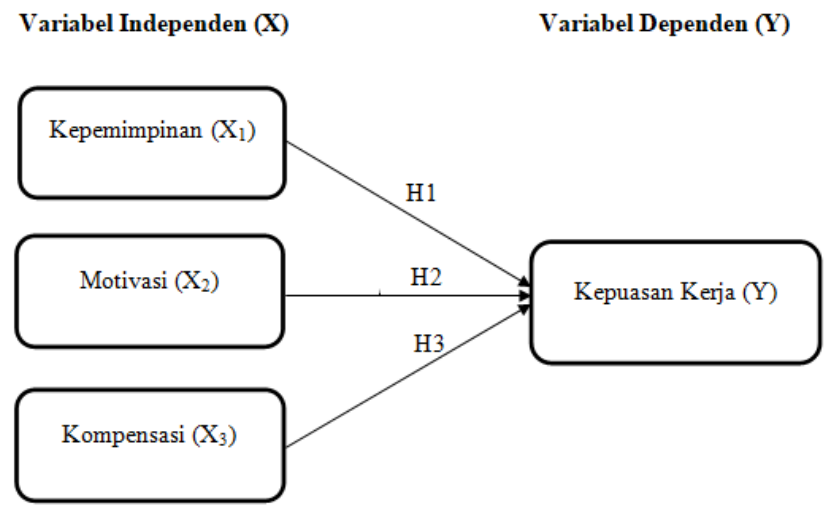

\section{Gambar 1 \\ Kerangka Penelitian}

Dari kerangka penelitian di atas, maka dapat disusun hipotesis dalam penelitian sebagai berikut ini:

H1 : Kepemimpinan mempunyai pengaruh yang signifikan terhadap kepuasan kerja karyawan

H2 : Motivasi mempunyai pengaruh yang signifikan terhadap kepuasan kerja karyawan

H3 : Kompensasi mempunyai pengaruh yang signifikan terhadap kepuasan kerja karyawan

\section{METODOLOGI PENELITIAN}

Metode penelitian yang digunakan pada penelitian ini adalah penelitian deskriptif. Populasi dalam penelitian ini adalah seluruh karyawan perusahaan importir alat berat PT XYZ di Jakarta. Metode pengambilan sampel pada penelitian ini adalah probability sampling, dimana teknik pengambilan sampel yang memberikan peluang atau kesempatan yang sama bagi setiap unsur atau anggota populasi untuk dipilih menjadi sampel. Sementara teknik pemilihan sampel yang digunakan dalam penelitian ini adalah simple random sampling. Sampel dalam penelitian ini sebanyak 115 orang karyawan PT XYZ di Jakarta.

Beberapa instrumen di adaptasi dari penelitian terdahulu untuk mengukur variabel penelitian, pengukuran objek penelitian diukur menggunakan skala Likert lima poin dengan 1 menunjukan "sangat tidak setuju" dan 5 menunjukan "sangat setuju".

Pengumpulan data pada penelitian ini dilakukan dengan pembagian kuesioner secara online dengan menggunakan google-form kepada seluruh karyawan perusahaan importir alat berat PT XYZ di Jakarta. Metode analisis data dalam penelitian ini menggunakan structure equation modeling (SEM) dengan bantuan program Smart PLS 3.3.2. Taraf signifikansi yang digunakan pada penelitian ini adalah sebesar 5\%. Operasional variabel penelitian ini diadaptasi dari Suwatno dan Priansa (2011:159) dengan rincian variabel kepemimpinan sebanyak 6 item, dari Wibowo (2011:162) dengan variabel motivasi sebanyak 7 item, dari Handoko (2012:56) dengan variabel kompensasi sebanyak 4 item, dan dari Luthans (2006:24) dengan variable kepuasan kerja karyawan sebanyak 6 item.

\section{Hasil Uji Statistik}

Hasil pengujian koefisien determinasi $\left(\mathrm{R}^{2}\right)$ dari penelitian ini menunjukkan nilai persentase variabel kepuasan kerja karyawan sebesar 70,2\%. Kemudian berdasarkan hasil 
pengujian predictive relevance $\left(\mathrm{Q}^{2}\right)$ yang menunjukan nilai sebesar 0,421 lebih besar dari 0 yang berarti bahwa konstruk variabel yang terdapat dalam penelitian ini relevan untuk mengukur model penelitian yang telah terbentuk sebelumnya dengan baik. Hasil analisis data secara singkat tertera pada Tabel 1 berikut ini:

Tabel 1

Hasil Pengujian Hipotesis

\begin{tabular}{llll}
\hline & Hipotesis & Coefficients & T Statistics \\
\hline H1 & Kepemimpinan -> Kepuasan Kerja Karyawan & 0.229 & $3,345^{*}$ \\
\hline H2 & Motivasi -> Kepuasan Kerja Karyawan & 0.167 & $2,742^{*}$ \\
\hline H3 & Kompensasi - Kepuasan Kerja Karyawan & 0.634 & $10,486^{*}$ \\
\hline $\mathrm{p}<0,05 ; * * \mathrm{p}<0,01$ &
\end{tabular}

Berdasarkan Tabel 1. di atas dapat ditarik kesimpulan bahwa variabel kompensasi memberikan kontribusi terbesar terhadap kepuasan kerja karyawan yang dibuktikan oleh nilai path coefficients sebesar 0.634. Sementara untuk hasil pengujian hipotesis variabel kepemimpinan dan motivasi memiliki pengaruh positif dan signifikan terhadap kepuasan kerja karyawan.

\section{Diskusi}

Hasil pengujian hipotesis pertama menunjukan variabel Kepemimpinan terbukti berpengaruh secara positif signifikan terhadap variabel Kepuasan Kerja Karyawan. Hasil penelitian ini didukung oleh hasil penelitian terdahulu yang dilakukan oleh Harahap dan Khair (2019), Sarittama dan Noerman (2017), Suryadharma, et al. (2016), Baihaqi (2015), Muttaqien (2014) serta Tamali dan Munasip (2019); yang menyatakan bahwa Kepemimpinan mempunyai pengaruh yang positif dan signifikan terhadap Kepuasan Kerja Karyawan.

Hasil pengujian hipotesis kedua menunjukan variabel Motivasi terbukti berpengaruh secara positif signifikan terhadap variabel Kepuasan Kerja Karyawan. Hasil penelitian ini didukung oleh hasil penelitian terdahulu yang dilakukan oleh Astuti dan Sudharma (2013), Baihaqi (2015), serta Sarittama dan Noerman (2017); yang menyatakan bahwa Motivasi berpengaruh secara positif dan signifikan terhadap Kepuasan Kerja Karyawan.

Hasil pengujian hipotesis ketiga menunjukan variabel Kompensasi terbukti berpengaruh secara positif signifikan terhadap variabel Kepuasan Kerja Karyawan. Hasil penelitian ini didukung oleh hasil penelitian terdahulu yang dilakukan oleh Astuti dan Sudharma (2013), Suryadharma, et al. (2016), Muttaqien (2014), serta Sarittama dan Noerman (2017); yang menyatakan bahwa Kompensasi berpengaruh secara positif dan signifikan terhadap Kepuasan Kerja Karyawan. Berbeda dengan hasil penelitian yang ditemukan oleh Tamali dan Munasip (2019), mereka menemukan bahwa Kompensasi secara partial berpengaruh secara negatif dan signifikan terhadap Kepuasan Kerja Karyawan, tetapi Kompensasi secara simultan berpengaruh positif dan signifikan terhadap Kepuasan Kerja Karyawan.

\section{KESIMPULAN}

Hasil penelitian menunjukkan jika H1, H2, dan $\mathrm{H} 3$ dinyatakan hipotesis tidak ditolak. Seluruh variabel (kepemimpinan, motivasi, dan kompensasi) memiliki pengaruh yang positif dan signifikan terhadap kepuasan kerja karyawan. Selanjutnya juga dapat disimpulkan bahwa yang mempunyai pengaruh terbesar terhadap kepuasan kerja karyawan adalah kompensasi yang diberikan oleh perusahaan.

\section{DAFTAR PUSTAKA}

Astuti, N. K. A. J. \& Sudharma, I. N. (2013). Pengaruh kompensasi dan motivasi terhadap kepuasan dan kinerja karyawan pada Hotel Bakung's Beach Cottages Kuta-Bali. EJurnal Manajemen Unud, 2(11), 1585-1594.

Baihaqi, A. (2015). Pengaruh Kepemimpinan, motivasi dan religiusitas terhadap kepuasan kerja karyawan pada PT. Unza Vitalis Salatiga. Jurnal Ekonomi dan Perbankan Syariah, 6(2), 43-64. 
Handoko, T. H. (2012). Manajemen Personalia dan Sumber Daya Manusia. Yogyakarta: BPFE.

Harahap, D. S. \& Khair, H. (2019). Pengaruh Kepemimpinan dan kompensasi terhadap kepuasan kerja melalui motivasi kerja. Jurnal Ilmiah Magister Manajemen Umsu, 2(1), 69-88.

Hasibuan, M. S. (2016). Manajemen Sumber Daya Manusia. Jakarta: PT Bumi Aksara.

Laminingrum, A. K. (2016). Pengaruh kompensasi terhadap motivasi kerja pada karyawan biro pelayanan sosial dasar di sekretariat daerah provinsi Jawa Barat. E-Proceeding of Management, 3(2), 1871-1879.

Lantara, I. W. (2017). Pengaruh motivasi kerja terhadap kinerja karyawan dengan kepuasan kerja sebagai variabel intervening PT. Indonesia Tourism Development Corporation (ITDC). E-Journal Jurusan Pendidikan Ekonomi, 10(2), 1-10.

Luthans, F. (2006). Perilaku Organisasi, (Edisi 10). Yogyakarta: Andi.

Mangkunegara, A. A. (2017). Manajemen Sumber Daya Manusia Perusahaan. Bandung: PT Remaja Rosdakarya.

Manullang, L. A. (2013). Teori Manajemen Komprehensif Integralistik. Jakarta: Salemba Empat.

Muttaqien, F. (2014). Pengaruh kepemimpinan dan kompensasi terhadap kepuasan kerja karyawan outsourcing pada PT BRI (Persero), Tbk. cabang Lumajang. Jurnal WIGA STIE Widya Gama Lumajang, 4(1), 19-33.

Robbins, S. \& Judge. (2011). Perilaku Organisasi. Jakarta: Salemba Empat.

Sarittama, N. \& Noerman, T. (2017). Strategi kepemimpinan, motivasi kerja dan kompensasi terhadap kepuasan kerja serta dampaknya pada kinerja karyawan generasi y PT. Bank BRI Wilayah I Jakarta. Jurnal Riset Perbankan Manajeman dan Akuntansi Perbanas, $1(1), 45-54$.

Siagian, S. P. (2002). Kiat Meningkatkan Produktivitas Kerja, (Cetakan Pertama). Jakarta: PT. Rineka Cipta.

Suryadharma, I. M. A., et al. (2016). Pengaruh kepemimpinan dan kompensasi terhadap kepuasan kerja dan kinerja karyawan (Studi pada PT BPR Sri Artha Lestari Denpasar). E-Jurnal Ekonomi dan Bisnis Universitas Udayana, 5(2), 335-358.

Sutrisno, E. (2013). Manajemen Sumber Daya Manusia. Jakarta: Kencana Prenada Media Group.

Suwatno \& Priansa, D. (2011). Manajemen SDM dalam Organisasi Publik dan Bisnis. Bandung: Alfabeta.

Tamali, H. \& Munasip, A. (2019). Pengaruh kompensasi, kepemimpinan, dan lingkungan kerja terhadap kepuasan kerja. Jurnal Ilmiah Magister Manajemen Umsu, 2(1), 55-68.

Usman, H. (2011). Manajemen. Jakarta: Bumi Aksara.

Werther, B. W. \& Davis, K. (2002). Human Resources and Personnel Management, (5 ${ }^{\text {th }}$ ed.). New York: McGraw Hill Inc.

Wibowo. (2015). Perilaku dalam Organisasi. Jakarta: PT Raja Grafindo Persada.

Wibowo. (2011). Manajemen Kinerja. Jakarta: PT Raja Grafindo Persada.

Yakub, Y. (2017). Pengaruh Keterlibatan kerja, budaya organisasi dan motivasi kerja terhadap kepuasan kerja pegawai. Islamic Banking and Finance Journal, 1(3), 273-290. 